\title{
Fixed points of weak $\alpha$-contraction type maps
}

\author{
Seong-Hoon $\mathrm{Cho}^{1 *}$ and Jong-Sook Bae ${ }^{2}$
}

${ }^{\text {*Correspondence: }}$

shcho@hanseo.ac.kr

1 Department of Mathematics,

Hanseo University, Seosan,

Chungnam 356-706, South Korea

Full list of author information is

available at the end of the article

\begin{abstract}
In this paper, the concept of weak $\alpha$-contraction type maps is introduced, and some new fixed point theorems for these maps are established. An example to illustrate the main result is given.
\end{abstract}

MSC: Primary $47 \mathrm{H} 10$; secondary $54 \mathrm{H} 25$

Keywords: fixed point; weak contraction map; weak $\alpha$-contraction type map

\section{Introduction and preliminaries}

Banach's contraction principle [1] is one of very important theorems in nonlinear analysis. Its significance lies in its vast applicability in a number of branches of mathematics. A lot of authors (see [2-14] and references therein) gave generalizations and extensions of it in many directions.

Alber and Guerre-Delabriere [15] introduced the notion of weakly contractive maps in Hilbert spaces and proved that any weakly contractive map defined on complete Hilbert spaces has a unique fixed point. Rhoades [16] reintroduced the notion of weakly contractive maps in the setting of metric spaces and proved that any weakly contractive map defined on complete metric spaces has a unique fixed point. Since then, many authors ([5, 6, 17-22] and reference therein) study fixed point results for weak contraction type maps.

The authors of [11] showed that fixed point generalizations to partial metric spaces can be obtained from the corresponding results in metric spaces, and they obtained fixed point results for weakly contractive type maps in partial metric spaces.

Especially, Harjani and Sadarangani [23] extended the result of Rhoades [16] to the case of partially ordered metric spaces.

Recently, Samet et al. [24] introduced the concept of $\alpha$ - $\psi$-contractive maps in metric spaces and obtained some fixed point results for these maps.

Afterward, the authors of [4] introduced the notion of $\alpha$ - $\psi$-quasi-contractive maps and obtained some fixed point results. The authors of [25] proved some approximate fixed point theorems, by introducing the notion of generalized $\alpha$-contractive maps. The authors of [26] gave some coupled fixed point results for $\alpha-\psi$-contractive type maps and gave the sufficient condition for the existence of a unique coupled fixed point for $\alpha-\psi$ contractive type maps. Recently, the authors of [27] gave applications of the result of [24] to the existence and uniqueness of a solution for the nonlinear fractional differential equations.

On the other hand, the authors of [28] obtained a generalization of the results of [24] to the case of multifunctions, by introducing the notions of $\alpha_{*}$-admissible multifunctions

\section{Springer}

C2014 Cho and Bae: licensee Springer. This is an Open Access article distributed under the terms of the Creative Commons Attribution License (http://creativecommons.org/licenses/by/2.0), which permits unrestricted use, distribution, and reproduction in any medium, provided the original work is properly cited. 
and $\alpha_{*}-\psi$-contractive multifunctions. Also, the authors of [29] gave a generalization of the results of [24] to the case of multifunctions, by introducing the notions of property $\left(C_{\alpha}\right), \alpha$-admissible multifunctions and $\alpha$ - $\psi$-Ćirić-contractive multifunctions.

Very recently, Cho [17] introduced the notion of weakly $\alpha$-contractive maps in metric spaces and proved a fixed point theorem for these maps.

In [17], the following theorem, which is a generalization of the results of Rhoades [16] and Harjani and Sadarangani [23], is proved.

Theorem 1.1 Let $(X, d)$ be a complete metric space, $\alpha: X \times X \rightarrow \mathbb{R}_{+}$be a function, and let $T: X \rightarrow X$ be a map. Suppose that the following are satisfied:

(1) $T$ is a weakly $\alpha$-contractive map, i.e.

$$
\alpha(x, y) d(T x, T y) \leq d(x, y)-\eta(d(x, y))
$$

for all $x, y \in X$, where $\eta:[0, \infty) \rightarrow[0, \infty)$ is a nondecreasing function such that $\eta$ is positive on $(0, \infty), \eta(0)=0$ and $\lim _{t \rightarrow \infty} \eta(t)=\infty$;

(2) for each $x, y, z \in X, \alpha(x, y) \geq 1$ and $\alpha(y, z) \geq 1$ implies $\alpha(x, z) \geq 1$;

(3) $T$ is $\alpha$-admissible, i.e. $\alpha(x, y) \geq 1$ implies $\alpha(T x, T y) \geq 1$;

(4) there exists $x_{0} \in X$ such that $\alpha\left(x_{0}, T x_{0}\right) \geq 1$;

(5) either $T$ is continuous or $\lim _{n \rightarrow \infty} \inf \alpha\left(T^{n} x_{0}, x\right)>0$ for any cluster point $x$ of $\left\{T^{n} x_{0}\right\}$.

Then $T$ has a fixed point in $X$. Further if, for all $x, y \in X$, there exists $z \in X$ such that $\alpha(x, z) \geq 1$ and $\alpha(y, z) \geq 1$, then $T$ has a unique fixed point.

In this paper, we introduce the concept of weakly $\alpha$-contractive type maps in metric spaces and establish some new fixed point theorems for these maps. We have generalizations of the results in the literature.

We denote by $\Psi$ the family of all functions $\psi: \mathbb{R}_{+}^{4} \rightarrow \mathbb{R}_{+}$such that

$\left(\psi_{1}\right) \psi$ is nondecreasing and continuous in each coordinate;

$\left(\psi_{2}\right) \psi(t, t, t, t) \leq t$ for all $t>0$;

$\left(\psi_{3}\right) \psi\left(t_{1}, t_{2}, t_{3}, t_{4}\right)=0$ if and only if $t_{1}=t_{2}=t_{3}=t_{4}=0$.

From now on, let $\eta: \mathbb{R}_{+} \rightarrow \mathbb{R}_{+}$be a nondecreasing function such that

(1) $\eta(t)>0$ for all $t>0$;

(2) $\eta(0)=0$.

Lemma 1.1 Let $(X, d)$ be a metric space, $\alpha: X \times X \rightarrow \mathbb{R}_{+}$be a function, and let $T: X \rightarrow X$ be a map. If conditions (2), (3) and (4) of Theorem 1.1 are satisfied, then we have

$$
\alpha\left(T^{i} x_{0}, T^{j} x_{0}\right) \geq 1
$$

for all $i, j \in \mathbb{N} \cup\{0\}(i<j)$.

Let $(X, d)$ be a cone metric space, and $\alpha: X \times X \rightarrow[0, \infty)$ be a function.

We say that $X$ satisfies condition $(B)$ [26] whenever, for each sequence $\left\{x_{n}\right\}$ in $X$ with $\alpha\left(x_{n}, x_{n+1}\right) \geq 1$ for all $n \in \mathbb{N}$ and $\lim _{n \rightarrow \infty} x_{n}=x$, we have $\alpha\left(x_{n}, x\right) \geq 1$ for all $n \in \mathbb{N}$.

Also, we say that $X$ satisfies condition $\left(C_{\alpha}\right)$ [29] whenever, for each sequence $\left\{x_{n}\right\}$ in $X$ with $\alpha\left(x_{n}, x_{n+1}\right) \geq 1$ for all $n \in \mathbb{N}$ and $\lim _{n \rightarrow \infty} x_{n}=x$, there exists a subsequence $\left\{x_{n(k)}\right\}$ of $\left\{x_{n}\right\}$ such that $\alpha\left(x_{n(k)}, x\right) \geq 1$ for all $k \in \mathbb{N}$. 
Lemma 1.2 Let $(X, d)$ be a metric space, and $\alpha: X \times X \rightarrow[0, \infty)$ be a function. We consider the following conditions:

(1) if $\left\{x_{n}\right\}$ is a sequence in $X$ such that $\alpha\left(x_{n}, x_{n+1}\right) \geq 1$ for all $n$, then $\lim _{n \rightarrow \infty} \sup \alpha\left(x_{n}, x\right) \geq 1$ for any cluster point $x$ of $\left\{x_{n}\right\}$

(2) $X$ satisfies condition $\left(C_{\alpha}\right)$;

(3) $X$ satisfies condition $(B)$.

Then (3) implies (2), and (2) implies (1).

\section{Fixed points}

Let $(X, d)$ be a metric space, and let $\alpha: X \times X \rightarrow[0, \infty)$ be a function and $\psi \in \Psi$. A mapping $T: X \rightarrow X$ is called weak $\alpha$-contractive type if, for all $x, y \in X$,

$$
\alpha(x, y) d(T x, T y) \leq q(x, y)-\eta(q(x, y))
$$

where $q(x, y)=\psi\left(d(x, y), d(x, T x), d(y, T y), \frac{1}{2}\{d(x, T y)+d(y, T x)\}\right)$.

Theorem 2.1 Let $(X, d)$ be a complete metric space. Suppose that a weak $\alpha$-contractive type map $T: X \rightarrow X$ satisfies the following:

(1) there exists $x_{0} \in X$ such that $\alpha\left(T^{i} x_{0}, T^{j} x_{0}\right) \geq 1$ for all $i, j \geq 0(i<j)$;

(2) either $T$ is continuous or

$$
\lim _{n \rightarrow \infty} \sup \alpha\left(T^{n} x_{0}, x\right) \geq 1
$$

for any cluster point $x$ of $\left\{T^{n} x_{0}\right\}$.

Then $T$ has a fixed point in $X$.

Proof Let $x_{0} \in X$ be such that $\alpha\left(T^{i} x_{0}, T^{j} x_{0}\right) \geq 1$ for all $i, j \in \mathbb{N} \cup\{0\}(i<j)$. Define a sequence $\left\{x_{n}\right\} \subset X$ by $x_{n+1}=T x_{n}$ for $n \in \mathbb{N} \cup\{0\}$.

If $x_{n}=x_{n+1}$ for some $n \in \mathbb{N} \cup\{0\}$, then $x_{n}$ is a fixed point of $T$, and the proof is finished. Assume that $x_{n} \neq x_{n+1}$ for all $n \in \mathbb{N} \cup\{0\}$.

From (2.1) we have

$$
\begin{aligned}
d\left(x_{n}, x_{n+1}\right) & =d\left(T x_{n-1}, T x_{n}\right) \leq \alpha\left(x_{n-1}, x_{n}\right) d\left(T x_{n-1}, T x_{n}\right) \\
& \leq q\left(x_{n-1}, x_{n}\right)-\eta\left(q\left(x_{n-1}, x_{n}\right)\right) .
\end{aligned}
$$

Here,

$$
\begin{aligned}
q\left(x_{n-1}, x_{n}\right) & =\psi\left(d\left(x_{n-1}, x_{n}\right), d\left(x_{n-1}, T x_{n-1}\right), d\left(x_{n}, T x_{n}\right), \frac{1}{2}\left\{d\left(x_{n}, T x_{n-1}\right)+d\left(x_{n-1}, T x_{n}\right)\right\}\right) \\
& =\psi\left(d\left(x_{n}, x_{n-1}\right), d\left(x_{n-1}, x_{n}\right), d\left(x_{n}, x_{n+1}\right), \frac{1}{2} d\left(x_{n-1}, x_{n+1}\right)\right) .
\end{aligned}
$$

Since $d\left(x_{n-1}, x_{n}\right)>0$, we have $q\left(x_{n-1}, x_{n}\right)>0$ and so $\eta\left(q\left(x_{n-1}, x_{n}\right)\right)>0$.

Thus, from (2.3) we have

$$
\begin{aligned}
d\left(x_{n}, x_{n+1}\right) & <q\left(x_{n-1}, x_{n}\right) \\
& \leq \psi\left(d\left(x_{n-1}, x_{n}\right), d\left(x_{n-1}, x_{n}\right), d\left(x_{n}, x_{n+1}\right), \frac{1}{2}\left\{d\left(x_{n-1}, x_{n}\right)+d\left(x_{n}, x_{n+1}\right)\right\}\right) .
\end{aligned}
$$


If $d\left(x_{n-1}, x_{n}\right) \leq d\left(x_{n}, x_{n+1}\right)$ for some $n \in \mathbb{N}$, then

$$
\begin{aligned}
d\left(x_{n}, x_{n+1}\right) & <\psi\left(d\left(x_{n-1}, x_{n}\right), d\left(x_{n-1}, x_{n}\right), d\left(x_{n}, x_{n+1}\right), \frac{1}{2}\left\{d\left(x_{n-1}, x_{n}\right)+d\left(x_{n}, x_{n+1}\right)\right\}\right) \\
& \leq \psi\left(d\left(x_{n}, x_{n+1}\right), d\left(x_{n}, x_{n+1}\right), d\left(x_{n}, x_{n+1}\right), d\left(x_{n}, x_{n+1}\right)\right) \leq d\left(x_{n}, x_{n+1}\right),
\end{aligned}
$$

which is a contradiction.

Hence, $d\left(x_{n}, x_{n+1}\right)<d\left(x_{n-1}, x_{n}\right)$ for all $n \in \mathbb{N}$. So the sequence $\left\{d\left(x_{n-1}, x_{n}\right)\right\}$ is decreasing. Thus, there exists $r \geq 0$ such that $\lim _{n \rightarrow \infty} d\left(x_{n-1}, x_{n}\right)=r$. Since $q\left(x_{n-1}, x_{n}\right) \leq$ $\psi\left(d\left(x_{n}, x_{n-1}\right), d\left(x_{n-1}, x_{n}\right), d\left(x_{n}, x_{n+1}\right), \frac{1}{2}\left\{d\left(x_{n-1}, x_{n}\right)+d\left(x_{n}, x_{n+1}\right)\right\}\right)$, we obtain $\lim _{n \rightarrow \infty} q\left(x_{n-1}\right.$, $\left.x_{n}\right) \leq \psi(r, r, r, r)$.

On the other hand, since $d\left(x_{n}, x_{n+1}\right) \geq r$ for all $n \in \mathbb{N}$, we obtain

$$
\begin{aligned}
\eta\left(q\left(x_{n-1}, x_{n}\right)\right) & =\eta\left(\psi\left(d\left(x_{n}, x_{n-1}\right), d\left(x_{n-1}, x_{n}\right), d\left(x_{n}, x_{n+1}\right), \frac{1}{2} d\left(x_{n-1}, x_{n+1}\right)\right)\right) \\
& \geq \eta(\psi(r, r, r, 0)) .
\end{aligned}
$$

Hence, $\lim _{n \rightarrow \infty} \eta\left(q\left(x_{n-1}, x_{n}\right)\right) \geq \eta(\psi(r, r, r, 0))$.

Letting $n \rightarrow \infty$ in (2.3), we have

$$
\begin{aligned}
r & \leq \lim _{n \rightarrow \infty} q\left(x_{n-1}, x_{n}\right)-\lim _{n \rightarrow \infty} \eta\left(q\left(x_{n-1}, x_{n}\right)\right) \\
& \leq \psi(r, r, r, r)-\eta(\psi(r, r, r, 0)) \leq r-\eta(\psi(r, r, r, 0)),
\end{aligned}
$$

which implies $\eta(\psi(r, r, r, 0))=0$, and so $\psi(r, r, r, 0)=0$. By $\left(\psi_{3}\right), r=0$. Thus,

$$
\lim _{n \rightarrow \infty} d\left(x_{n}, x_{n+1}\right)=0
$$

We now show that $\left\{x_{n}\right\}$ is a Cauchy sequence.

On the contrary, assume that $\left\{x_{n}\right\}$ is not a Cauchy sequence.

Then there exists $\epsilon>0$ for which we can find subsequences $\left\{x_{m(k)}\right\}$ and $\left\{x_{n(k)}\right\}$ of $\left\{x_{n}\right\}$ such that $m(k)$ is the smallest index for which

$$
m(k)>n(k)>k, \quad d\left(x_{m(k)}, x_{n(k)}\right) \geq \epsilon \quad \text { and } \quad d\left(x_{m(k)-1}, x_{n(k)}\right)<\epsilon .
$$

From the above inequalities, $\epsilon \leq d\left(x_{m(k)}, x_{n(k)}\right) \leq d\left(x_{m(k)}, x_{m(k)-1}\right)+d\left(x_{m(k)-1}, x_{n(k)}\right)<$ $d\left(x_{m(k)}, x_{m(k)-1}\right)+\epsilon$.

By taking $k \rightarrow \infty$ in the above inequality and using (2.6), we have

$$
\lim _{k \rightarrow \infty} d\left(x_{m(k)}, x_{n(k)}\right)=\epsilon .
$$

By using (2.6), (2.7), and the triangle inequality, we obtain

$$
\begin{aligned}
& \lim _{k \rightarrow \infty} d\left(x_{m(k)-1}, x_{n(k)-1}\right)=\epsilon, \\
& \lim _{k \rightarrow \infty} d\left(x_{m(k)-1}, x_{n(k)}\right)=\epsilon, \\
& \lim _{k \rightarrow \infty} d\left(x_{m(k)}, x_{n(k)-1}\right)=\epsilon .
\end{aligned}
$$


From (2.1) we have

$$
\begin{aligned}
d\left(x_{n(k)}, x_{m(k)}\right) & =d\left(T x_{n(k)-1}, T x_{m(k)-1}\right) \\
& \leq \alpha\left(x_{n(k)-1}, x_{m(k)-1}\right) d\left(T x_{n(k)-1}, T x_{m(k)-1}\right) \\
& \leq q\left(x_{n(k)-1}, x_{m(k)-1}\right)-\eta\left(q\left(x_{n(k)-1}, x_{m(k)-1}\right)\right),
\end{aligned}
$$

where

$$
\begin{aligned}
q\left(x_{n(k)-1}, x_{m(k)-1}\right)= & \psi\left(d\left(x_{n(k)-1}, x_{m(k)-1}\right), d\left(x_{n(k)-1}, x_{n(k)}\right), d\left(x_{m(k)-1}, x_{m(k)}\right)\right. \\
& \left.\frac{1}{2}\left\{d\left(x_{n(k)}, x_{m(k)-1}\right)+d\left(x_{n(k)-1}, x_{m(k)}\right)\right\}\right) .
\end{aligned}
$$

Since $d\left(x_{m(k)-1}, x_{n(k)-1}\right)>\frac{1}{2} \epsilon, d\left(x_{m(k)-1}, x_{n(k)}\right)>\frac{1}{2} \epsilon$ and $d\left(x_{m(k)}, x_{n(k)-1}\right)>\frac{1}{2} \epsilon$ for sufficiently large $n$, we obtain

$$
\lim _{k \rightarrow \infty} \eta\left(q\left(x_{n(k)-1}, x_{m(k)-1}\right)\right) \geq \eta\left(\psi\left(\frac{1}{2} \epsilon, 0,0, \frac{1}{2} \epsilon\right)\right) .
$$

Letting $k \rightarrow \infty$ in the above inequality (2.9), we have

$$
\epsilon \leq \psi(\epsilon, 0,0, \epsilon)-\lim _{k \rightarrow \infty} \eta\left(q\left(x_{n(k)-1}, x_{m(k)-1}\right)\right) \leq \epsilon-\eta\left(\psi\left(\frac{1}{2} \epsilon, 0,0, \frac{1}{2} \epsilon\right)\right)
$$

which implies $\eta\left(\psi\left(\frac{1}{2} \epsilon, 0,0, \frac{1}{2} \epsilon\right)\right)=0$, and so $\psi\left(\frac{1}{2} \epsilon, 0,0, \frac{1}{2} \epsilon\right)=0$. By $\left(\psi_{3}\right), \epsilon=0$, which is a contradiction. Hence, $\left\{x_{n}\right\}$ is a Cauchy sequence. It follows from the completeness of $X$ that there exists $x_{*} \in X$ such that $\lim _{n \rightarrow \infty} x_{n}=x_{*}$.

If $T$ is continuous, then $d\left(x_{*}, T x_{*}\right)=\lim _{n \rightarrow \infty} d\left(x_{*}, T x_{n}\right)=\lim _{n \rightarrow \infty} d\left(x_{*}, x_{n+1}\right)=0$. Hence, $x_{*}=T x_{*}$.

Assume that condition (2.2) holds.

Then $\lim _{n \rightarrow \infty} \sup \alpha\left(x_{n}, x_{*}\right) \geq 1$.

Since $\eta$ and $\psi$ are nondecreasing, we have

$$
\begin{aligned}
\eta\left(q\left(x_{n}, x_{*}\right)\right) & =\eta\left(\psi\left(d\left(x_{n}, x_{*}\right), d\left(x_{n}, x_{n+1}\right), d\left(x_{*}, T x_{*}\right), \frac{1}{2}\left\{d\left(x_{n}, T x_{*}\right)+d\left(x_{*}, x_{n+1}\right)\right\}\right)\right) \\
& \geq \eta\left(\psi\left(0,0, d\left(x_{*}, T x_{*}\right), 0\right)\right) \quad \text { for all } n \in \mathbb{N} .
\end{aligned}
$$

Thus, $\lim _{n \rightarrow \infty} \eta\left(q\left(x_{n}, x_{*}\right)\right) \geq \eta\left(\psi\left(0,0, d\left(x_{*}, T x_{*}\right), 0\right)\right)$. Since $\lim _{n \rightarrow \infty} q\left(x_{n}, x_{*}\right)=\psi\left(0,0, d\left(x_{*}\right.\right.$, $\left.\left.T x_{*}\right), \frac{1}{2} d\left(x_{*}, T x_{*}\right)\right)$, from (2.1) we obtain

$$
\alpha\left(x_{n}, x_{*}\right) d\left(x_{n+1}, T x_{*}\right)=\alpha\left(x_{n}, x_{*}\right) d\left(T x_{n}, T x_{*}\right) \leq q\left(x_{n}, x_{*}\right)-\eta\left(q\left(x_{n}, x_{*}\right)\right) .
$$

By taking the limit supremum in the above inequality (2.10), we have

$$
\begin{aligned}
d\left(x_{*}, T x_{*}\right) & \leq \psi\left(0,0, d\left(x_{*}, T x_{*}\right), \frac{1}{2} d\left(x_{*}, T x_{*}\right)\right)-\eta\left(\psi\left(0,0, d\left(x_{*}, T x_{*}\right), 0\right)\right) \\
& \leq d\left(x_{*}, T x_{*}\right)-\eta\left(\psi\left(0,0, d\left(x_{*}, T x_{*}\right), 0\right)\right)
\end{aligned}
$$


which implies $\eta\left(\psi\left(0,0, d\left(x_{*}, T x_{*}\right), 0\right)\right)=0$, and so $\psi\left(0,0, d\left(x_{*}, T x_{*}\right), 0\right)=0$. By $\left(\psi_{3}\right), d\left(x_{*}\right.$, $\left.T x_{*}\right)=0$, and hence, $x_{*}=T x_{*}$.

In Theorem 2.1, if we take $\psi\left(t_{1}, t_{2}, t_{3}, t_{4}\right)=\max \left\{t_{1}, t_{2}, t_{3}, t_{4}\right\}$, then we have the following result.

Corollary 2.2 Let $(X, d)$ be a complete metric space, and let $\alpha: X \times X \rightarrow \mathbb{R}_{+}$be a function. Suppose that a map $T: X \rightarrow X$ satisfies the following:

(1) $\alpha(x, y) d(T x, T y) \leq M(x, y)-\eta(M(x, y))$ for all $x, y \in X$, where $M(x, y)=\max \left\{d(x, y), d(x, T x), d(y, T y), \frac{1}{2}\{d(x, T y)+d(y, T x)\}\right\} ;$

(2) there exists $x_{0} \in X$ such that $\alpha\left(T^{i} x_{0}, T^{j} x_{0}\right) \geq 1$ for all $i, j \geq 0(i<j)$;

(3) either $T$ is continuous or

$$
\lim _{n \rightarrow \infty} \sup \alpha\left(T^{n} x_{0}, x\right) \geq 1
$$

for any cluster point $x$ of $\left\{T^{n} x_{0}\right\}$.

Then $T$ has a fixed point in $X$.

If we take $\phi(t)=t-\eta(t)$ for all $t \geq 0$, then we have the following result.

Corollary 2.3 Let $(X, d)$ be a complete metric space, and let $\alpha: X \times X \rightarrow \mathbb{R}_{+}$be a function. Suppose that a map $T: X \rightarrow X$ satisfies the following:

(1) $\alpha(x, y) d(T x, T y) \leq \phi(q(x, y))$, where $\phi: \mathbb{R}_{+} \rightarrow \mathbb{R}_{+}$is a nondecreasing function such that $\phi(0)=0$ and $\phi(t)<t$ for all $t>0$;

(2) there exists $x_{0} \in X$ such that $\alpha\left(T^{i} x_{0}, T^{j} x_{0}\right) \geq 1$ for all $i, j \geq 0(i<j)$;

(3) either $T$ is continuous or

$$
\lim _{n \rightarrow \infty} \sup \alpha\left(T^{n} x_{0}, x\right) \geq 1
$$

for any cluster point $x$ of $\left\{T^{n} x_{0}\right\}$.

Then $T$ has a fixed point in $X$.

Corollary 2.4 Let $(X, d)$ be a complete metric space, and let $\alpha: X \times X \rightarrow \mathbb{R}_{+}$be a function. Suppose that a map $T: X \rightarrow X$ satisfies the following:

(1) $\alpha(x, y) d(T x, T y) \leq \phi(M(x, y))$;

(2) there exists $x_{0} \in X$ such that $\alpha\left(T^{i} x_{0}, T^{j} x_{0}\right) \geq 1$ for all $i, j \geq 0(i<j)$;

(3) either $T$ is continuous or

$$
\lim _{n \rightarrow \infty} \sup \alpha\left(T^{n} x_{0}, x\right) \geq 1
$$

for any cluster point $x$ of $\left\{T^{n} x_{0}\right\}$.

Then $T$ has a fixed point in $X$.

Remark 2.1 (1) If we have $\alpha(x, y)=1$ for all $x, y \in X$ in Corollary 2.2, Corollary 2.2 becomes Corollary 2.2 of [22].

(2) Corollary 2.4 is a generalization of Theorem 3.7 of [29]. 
Theorem 2.5 Let $(X, d)$ be a complete metric space, and let $\alpha: X \times X \rightarrow \mathbb{R}_{+}$be a function. Suppose that a map $T: X \rightarrow X$ satisfies the following:

(1) $\alpha(x, y) d(T x, T y) \leq \varphi(d(x, y))-\eta(\varphi(d(x, y)))$, where $\varphi: \mathbb{R}_{+} \rightarrow \mathbb{R}_{+}$is a nondecreasing and continuous function such that $\varphi(t)=0$ if and only if $t=0$ and $\varphi(t)<t$ for all $t>0$;

(2) there exists $x_{0} \in X$ such that $\alpha\left(T^{i} x_{0}, T^{j} x_{0}\right) \geq 1$ for all $i, j \geq 0(i<j)$;

(3) either $T$ is continuous or

$$
\lim _{n \rightarrow \infty} \sup \alpha\left(T^{n} x_{0}, x\right)>0
$$

for any cluster point $x$ of $\left\{T^{n} x_{0}\right\}$.

Then $T$ has a fixed point in $X$.

Proof Let $x_{0} \in X$ such that $\alpha\left(T^{i} x_{0}, T^{j} x_{0}\right) \geq 1$ for all $i, j \geq 0(i<j)$. Let $x_{n}=T x_{n-1}$ for all $n \in \mathbb{N}$. By similar argument with the proof of Theorem 2.1, we see that $\left\{x_{n}\right\}$ is a Cauchy sequence. Let $\lim _{n \rightarrow \infty} x_{n}=x_{*} \in X$.

If $T$ is continuous, then $\lim _{n \rightarrow \infty} x_{n+1}=T x_{*}$. Hence, $x_{*}=T x_{*}$.

Suppose that condition (2.11) is satisfied.

Then $p:=\lim _{n \rightarrow \infty} \sup \alpha\left(x_{n}, x_{*}\right)>0$. Thus, from (1) we have

$$
\begin{aligned}
\alpha\left(x_{n}, x_{*}\right) d\left(x_{n+1}, T x_{*}\right) & =\alpha\left(x_{n}, x_{*}\right) d\left(T x_{n}, T x_{*}\right) \\
& \leq \varphi\left(d\left(x_{n}, x_{*}\right)\right)-\eta\left(\varphi\left(d\left(x_{n}, x_{*}\right)\right)\right) \\
& \leq \varphi\left(d\left(x_{n}, x_{*}\right)\right) .
\end{aligned}
$$

By taking the limit supremum in the above inequality, we obtain

$$
p d\left(x_{*}, T x_{*}\right) \leq \lim _{n \rightarrow \infty} \varphi\left(d\left(x_{n}, x_{*}\right)\right)=\varphi(0)=0 .
$$

Since $p>0, d\left(x_{*}, T x_{*}\right)=0$. Thus, $x_{*}=T x_{*}$.

Remark 2.2 (1) In Theorem 2.1, if we replace condition (2.2) by

$$
\lim _{n \rightarrow \infty} \inf \alpha\left(T^{n} x_{0}, x\right) \geq 1
$$

for any cluster point $x$ of $\left\{T^{n} x_{0}\right\}$, then the conclusion holds.

(2) If we replace condition (2.11) in Theorem 2.5 by

$$
\lim _{n \rightarrow \infty} \inf \alpha\left(T^{n} x_{0}, x\right)>0
$$

for any cluster point $x$ of $\left\{T^{n} x_{0}\right\}$, then the conclusion holds.

Remark 2.3 By taking $\varphi(t)=t$ for all $t \geq 0$ and using Remark 2.2(2), Theorem 2.5 reduces to Theorem 2.1 of [17].

If we take $\varphi(t)=t$ and $\phi(t)=t-\eta(t)$ for all $t \geq 0$, then we have the following result. 
Corollary 2.6 Let $(X, d)$ be a complete metric space, and let $\alpha: X \times X \rightarrow \mathbb{R}_{+}$be a function. Suppose that a map $T: X \rightarrow X$ satisfies the following:

(1) $\alpha(x, y) d(T x, T y) \leq \phi(d(x, y))$, where $\phi: \mathbb{R}_{+} \rightarrow \mathbb{R}_{+}$is a nondecreasing function such that $\phi(t)=0$ if and only if $t=0$ and $\phi(t)<t$ for all $t>0$;

(2) there exists $x_{0} \in X$ such that $\alpha\left(T^{i} x_{0}, T^{j} x_{0}\right) \geq 1$ for all $i, j \geq 0(i<j)$;

(3) either $T$ is continuous or

$$
\lim _{n \rightarrow \infty} \sup \alpha\left(T^{n} x_{0}, x\right)>0
$$

for any cluster point $x$ of $\left\{T^{n} x_{0}\right\}$.

Then $T$ has a fixed point in $X$.

Remark 2.4 Corollary 2.6 is a generalization of Theorem 2.1 and Theorem 2.2 of [24].

We give an example to illustrate Theorem 2.1.

Example 2.1 Let $X=[0, \infty)$, and let $d(x, y)=|x-y|$ for all $x, y \in X$. Let $\psi\left(t_{1}, t_{2}, t_{3}, t_{4}\right)=$ $\max \left\{t_{1}, t_{2}, t_{3}, t_{4}\right\}$ for all $t_{1}, t_{2}, t_{3}, t_{4} \geq 0$.

We define a mapping $T: X \rightarrow X$ by

$$
T x= \begin{cases}\frac{1}{2} x & (0 \leq x \leq 1), \\ 2 x & (x>1)\end{cases}
$$

Then $T$ is not a generalized weak contraction (for the definition of generalized weak contraction; see [22]). In fact, $d(T 1, T 2)=\frac{7}{2}>\frac{9}{4}=q(2,1)>q(2,1)-\eta(q(2,1))$ for all $\eta \in \Psi$, where $q(2,1)=\max \left\{d(2,1), d(1, T 1), d(2, T 2), \frac{1}{2}\{d(1, T 2)+d(2, T 1)\}\right\}$.

We define a function $\alpha: X \times X \rightarrow[0, \infty)$ by

$$
\alpha(x, y)= \begin{cases}1 & (0 \leq x, y \leq 1) \\ 0 & \text { otherwise }\end{cases}
$$

Obviously, condition (1) of Theorem 2.1 is satisfied with $x_{0}=1$. Condition (2) of Theorem 2.1 is satisfied with $T^{n} x_{0}=\frac{1}{2^{n}}$. It is easy to see that $T$ is a weak $\alpha$-contractive type map with $\eta(t)=\frac{1}{2} t$ for all $t \geq 0$.

Thus, all hypotheses of Theorem 2.1 are satisfied, and $T$ has a fixed point $x_{*}=0$.

\section{Common fixed points}

Let $(X, d)$ be a metric space, and let $S, T: X \rightarrow X$ be maps. Then:

(1) $S$ and $T$ are called weakly commuting [30] if

$$
d(S T x, T S x) \leq d(S x, T x)
$$

for all $x \in X$;

(2) $S$ and $T$ are called compatible [31] if

$$
\lim _{n \rightarrow \infty} d\left(S T x_{n}, T S x_{n}\right)=0
$$

whenever $\left\{x_{n}\right\}$ is a sequence such that $\lim _{n \rightarrow \infty} S x_{n}=\lim _{n \rightarrow \infty} T x_{n}=x$ for some $x \in X$; 
(3) $S$ and $T$ are called weakly compatible [32] (or pointwise R-weakly commuting [33]) if

$$
S T x=T S x,
$$

whenever $S x=T x$.

Note that commutativity implies weak commutativity, weak commutativity implies compatibility, and compatibility implies weak compatibility.

To prove the following common fixed point results, we use Lemma 2.1 and the technique in [34].

Theorem 3.1 Let $(X, d)$ be a complete metric space, and let $\alpha: X \times X \rightarrow \mathbb{R}_{+}$be a function. Let $S, T: X \rightarrow X$ be maps such that $T(X) \subset S(X)$ and $\alpha(S x, S y) \leq \alpha(x, y)$ for all $x, y \in X$.

Suppose that the following are satisfied:

(1) there exists $\psi \in \Psi$ such that, for all $x, y \in X$,

$$
\alpha(x, y) d(T x, T y) \leq q(S x, S y)-\eta(q(S x, S y))
$$

where $q(S x, S y)=\psi\left(d(S x, S y), d(S x, T x), d(S y, T y), \frac{1}{2}\{d(S x, T y)+d(S y, T x)\}\right) ;$

(2) there exists $x_{0} \in X$ such that $T x_{n}=S x_{n+1}$ for all $n \in \mathbb{N} \cup\{0\}$ and $\alpha\left(T x_{i}, T x_{j}\right) \geq 1$ for all $i, j \in \mathbb{N} \cup\{0\}(i<j)$;

(3) either $T$ is continuous or

$$
\lim _{n \rightarrow \infty} \sup \alpha\left(T x_{n}, x\right) \geq 1
$$

for any cluster point $x$ of $\left\{T x_{n}\right\}$.

If $S(X)$ is a complete subspace of $X$, then $S$ and $T$ have a coincidence point.

Moreover, suppose that for all coincidence point $z$ of $S$ and $T$

$$
\alpha(T z, z) \geq 1 .
$$

If $S$ and $T$ are weakly compatible, then $S$ and $T$ have a common fixed point in $X$.

Proof By Lemma 2.1 of [34], there exists a subset $Y$ of $X$ such that $S(Y)=S(X)$ and $S: Y \rightarrow$ $X$ is one-to-one.

Define a map $A: S(Y) \rightarrow S(Y)$ by $A(S x)=T x$. Then $A$ is well defined, because $A$ is oneto-one.

From (3.1) we have

$$
\begin{aligned}
\alpha(S x, S y) d(A(S x), A(S y)) & =\alpha(x, y) d(T x, T y) \\
& \leq q(S x, S y)-\eta(q(S x, S y)) \quad \text { for all } S x, S y \in S(Y) .
\end{aligned}
$$

Hence, $A$ is a weak $\alpha$-contractive type map on $S(X)$.

Let $x_{0} \in X$ be fixed.

Since $T(X) \subset S(X)$, we can find a sequence $\left\{x_{n}\right\}$ of points in $X$ such that $T x_{n}=S x_{n+1}$ for all $n \in \mathbb{N} \cup\{0\}$. Then we have $A^{n}\left(S x_{0}\right)=T x_{n-1}$ for all $n \in \mathbb{N}$. Thus, $\alpha\left(A^{i}\left(S x_{0}\right), A^{j}\left(S x_{0}\right)\right)=$ $\alpha\left(T x_{i-1}, T x_{j-1}\right) \geq 1$ for all $i, j \in \mathbb{N}(i<j)$. 
If $T$ is continuous, then so is $A$.

Also, $\lim _{n \rightarrow \infty} \sup \alpha\left(A^{n}\left(S x_{0}\right), x\right)=\lim _{n \rightarrow \infty} \sup \alpha\left(T x_{n-1}, x\right)$ for any $x \in X$.

Thus, condition (3) implies either that $A$ is continuous or that

$$
\lim _{n \rightarrow \infty} \sup \alpha\left(A^{n}\left(S x_{0}\right), x\right) \geq 1
$$

for all cluster points $x$ of $\left\{A^{n}\left(S x_{0}\right)\right\}$.

By Theorem 2.1, $A$ has a fixed point in $S(X)$. That is, there exists $\bar{x} \in X$ such that $A(S \bar{x})=$ $S \bar{x}$. By definition of $A, S \bar{x}=T \bar{x}$. Thus, $\bar{x}$ is a coincidence point of $S$ and $T$.

We now show the existence of common fixed points of $S$ and $T$ with their weak compatibility.

Suppose that (3.2) holds and that $S$ and $T$ are weakly compatible.

Let $z=S \bar{x}=T \bar{x}$. Then $S z=T z$. Since $\alpha(z, \bar{x})=\alpha(T \bar{x}, \bar{x}) \geq 1$, from (3.1) we have

$$
\begin{aligned}
d(T z, z) & =d(T z, T \bar{x}) \\
& \leq \alpha(z, \bar{x}) d(T z, T \bar{x}) \\
& \leq q(S z, S \bar{x})-\eta(q(S z, S \bar{x})),
\end{aligned}
$$

where $q(S z, S \bar{x})=\psi\left(d(S z, S \bar{x}), d(T z, T z), d(z, z), \frac{1}{2}\{d(T z, z)+d(z, T z)\}\right)=\psi(d(T z, z), 0,0$, $d(T z, z))$.

Thus, we have $d(T z, z) \leq d(T z, z)-\eta(\psi(d(T z, z), 0,0, d(T z, z)))$, which implies $\eta(\psi(d(T z$, $z), 0,0, d(T z, z)))=0$, and so $\psi(d(T z, z), 0,0, d(T z, z))=0$. Hence, $d(T z, z)=0$ or $z=T z$. Thus, $z=S z=T z$, and $z$ is a common fixed point.

Theorem 3.2 Let $(X, d)$ be a complete metric space, and let $\alpha: X \times X \rightarrow \mathbb{R}_{+}$be a function. Let $S, T: X \rightarrow X$ be maps such that $T(X) \subset S(X)$ and $\alpha(S x, S y) \leq \alpha(x, y)$ for all $x, y \in X$.

Suppose that the following are satisfied:

(1) $\alpha(x, y) d(T x, T y) \leq \varphi(d(S x, S y))-\eta(\varphi(d(S x, S y)))$, where $\varphi: \mathbb{R}_{+} \rightarrow \mathbb{R}_{+}$is a nondecreasing and continuous function such that $\varphi(t)=0$ if and only if $t=0$ and $\varphi(t)<t$ for all $t>0$;

(2) there exists $x_{0} \in X$ such that $T x_{n}=S x_{n+1}$ for all $n \in \mathbb{N} \cup\{0\}$ and $\alpha\left(T x_{i}, T x_{j}\right) \geq 1$ for all $i, j \in \mathbb{N} \cup\{0\}(i<j)$;

(3) either $T$ is continuous or

$$
\lim _{n \rightarrow \infty} \sup \alpha\left(T x_{n}, x\right)>0
$$

for any cluster point $x$ of $\left\{T x_{n}\right\}$.

If $S(X)$ is a complete subspace of $X$, then $S$ and $T$ have a coincidence point in $X$.

Moreover, suppose that for all coincidence point $z$ of $S$ and $T$

$$
\alpha(T z, z) \geq 1
$$

If $S$ and $T$ are weakly compatible, then $S$ and $T$ have a common fixed point in $X$.

Proof Let $A$ be the map on $S(X)$ defined as in the proof of Theorem 3.1. 
Then from (1) we have

$$
\begin{aligned}
& \alpha(S x, S y) d(A(S x), A(S y)) \alpha(x, y) d(T x, T y) \\
& \quad \leq \varphi(d(S x, S y))-\eta(\varphi(d(S x, S y))) \quad \text { for all } S x, S y \in S(X) .
\end{aligned}
$$

As in the proof of Theorem 3.1, $A^{n}\left(S x_{0}\right)=T x_{n-1}$ for all $n \in \mathbb{N} \cup\{0\}$. Thus, $\alpha\left(A^{i}\left(S x_{0}\right)\right.$, $\left.A^{j}\left(S x_{0}\right)\right)=\alpha\left(T x_{i-1}, T x_{j-1}\right) \geq 1$ for all $i, j \in \mathbb{N}(i<j)$.

Condition (3) implies either that $A$ is continuous or that

$$
\lim _{n \rightarrow \infty} \sup \alpha\left(A^{n}\left(S x_{0}\right), x\right)>0
$$

for all cluster points $x$ of $\left\{A^{n}\left(S x_{0}\right)\right\}$.

By Theorem 2.5, $A$ has a fixed point in $S(X)$, i.e. there exists $\bar{x} \in X$ such that $A(S \bar{x})=S \bar{x}$, and so $S \bar{x}=T \bar{x}$. Thus $\bar{x}$ is a coincidence point of $S$ and $T$.

Suppose that (3.2) holds and that $S$ and $T$ are weakly compatible.

Let $z=S \bar{x}=T \bar{x}$. Then $S z=T z$. Since $\alpha(z, \bar{x})=\alpha(T \bar{x}, \bar{x}) \geq 1$, from condition (1) we have

$$
\begin{aligned}
d(T z, z) & =d(T z, T \bar{x}) \\
& \leq \alpha(z, \bar{x}) d(T z, T \bar{x}) \\
& \leq \varphi(d(S z, S \bar{x}))-\eta(\varphi(d(S z, S \bar{x})) \\
& =\varphi(d(T z, z))-\eta(\varphi(d(T z, z))) .
\end{aligned}
$$

If $d(T z, z)>0$, then $d(T z, z)<d(T z, z)-\eta(\varphi(d(T z, z)))$, which is a contradiction. Hence, $d(T z, z)=0$, or $z=T z$. Thus, $z=S z=T z$, and $z$ is a common fixed point.

\section{Competing interests}

The authors declare that they have no competing interests.

\section{Authors' contributions}

All authors contributed equally and significantly in writing this paper. All authors read and approved the final manuscript.

\section{Author details}

'Department of Mathematics, Hanseo University, Seosan, Chungnam 356-706, South Korea. ${ }^{2}$ Department of Mathematics, Moyngji University, Yongin, Gyeonggi 449-728, South Korea.

\section{Acknowledgements}

The authors express their gratitude to the referees for their helpful suggestions which improved final version of this paper.

Received: 29 April 2014 Accepted: 24 July 2014 Published: 18 Aug 2014

\section{References}

1. Banach, S: Sur les opérations dans les ensembles abstraits et leur applications aux équations intégrales. Fundam. Math. 3, 133-181 (1922)

2. Agarwal, RP, El-Gebeily, MA, O’Regan, D: Generalized contractions in partially ordered metric spaces. Appl. Anal. 87, 1-8 (2008)

3. Cho, SH, Bae, JS: Common fixed point theorems for mappings satisfying property (E.A) on cone metric spaces. Math. Comput. Model. 53, 945-951 (2011)

4. Cho, SH, Bae, JS: Fixed point theorems for $\alpha$ - $\psi$-quasi-contractive mappings in metric spaces. Fixed Point Theory Appl. 2013, 268 (2013)

5. Choudhury, BS, Metiya, N: Fixed points of weak contractions in cone metric spaces. Nonlinear Anal. 72, 1589-1593 (2010)

6. Choudhury, BS, Konar, P, Rhoades, BE, Metiya, N: Fixed point theorems for generalized weakly contractive mappings. Nonlinear Anal. 74, 2116-2126 (2011) 
7. Ćirić, LB: Generalized contractions and fixed-point theorems. Publ. Inst. Math. (Belgr.) 12(26), 19-26 (1971)

8. Ćirić, LB: Fixed-points for generalized multi-valued mappings. Mat. Vesn. 9(24), 265-272 (1972)

9. Ćirić, LB: A generalization of Banach's contraction principle. Proc. Am. Math. Soc. 45, 267-273 (1974)

10. Fang, JX, Gao, Y: Common fixed point theorems under strict contractive conditions in Menger spaces. Nonlinear Anal. 70, 184-193 (2009)

11. Haghi, RH, Rezapour, S, Shahzad, N: Be careful on partial metric fixed point results. Topol. Appl. 160, $450-454$ (2013)

12. Khamsi, MA, Kreinovich, VY: Fixed point theorems for dissipative mappings in complete probabilistic metric spaces. Math. Jpn. 44, 513-520 (1996)

13. Rezapour, S, Hamlbarani, R: Some notes on the paper 'Cone metric spaces and fixed point theorems of contractive mappings'. J. Math. Anal. Appl. 345, 719-724 (2008)

14. Yang, SK, Bae, JS, Cho, SH: Coincidence and common fixed and periodic point theorems in cone metric spaces. Comput. Math. Appl. 61, 170-177 (2011)

15. Alber, Yl, Guerre-Delabriere, S: Principles of weakly contractive maps in Hilbert spaces. In: Goldberg, I, Lyubich, Y (eds.) New Results in Operator Theory. Advances and Appl., vol. 98, pp. 7-22. Birkhäuser, Basel (1997)

16. Rhoades, BE: Some theorems on weakly contractive maps. Nonlinear Anal. TMA 47(4)، 2683-2693 (2001)

17. Cho, SH: A fixed point theorem for weakly $\alpha$-contractive mappings with application. Appl. Math. Sci. 7(60), 2953-2965 (2013)

18. Ćirić, LB, Samet, B, Cakić, N, Damjanović, B: Coincidence and fixed point theorems for generalized $(\psi, \phi)$-weak nonlinear contraction in ordered K-metric spaces. Comput. Math. Appl. 62, 3305-3316 (2011)

19. Chidume, $\mathrm{CE}$, Zegeye, $\mathrm{H}$, Aneke, SJ: Approximation of fixed points of weakly contractive nonself maps in Banach spaces. J. Math. Anal. Appl. 270(1), 189-199 (2002)

20. Dorić, D: Common fixed point for generalized $(\psi, \varphi)$-weak contractions. Appl. Math. Lett. 22, 1896-1900 (2009)

21. Dutta, PN, Choudhury, BS: A generalisation of contraction principle in metric spaces. Fixed Point Theory Appl. 2008, Article ID 406368 (2008)

22. Zhang, Q, Song, Y: Fixed point theory for generalized $\phi$-weak contractions. Appl. Math. Lett. 22(1), 75-78 (2009)

23. Harjani, J, Sadarangani, K: Fixed point theorems for weakly contractive mappings in partially ordered sets. Nonlinear Anal. 71, 3403-3410 (2009)

24. Samet, B, Vetro, C, Vetro, P: Fixed point theorems for $\alpha$ - $\psi$-contractive type mappings. Nonlinear Anal. 75, 2154-2165 (2012)

25. Miandaragh, MA, Postolache, M, Rezapour, S: Some approximate fixed point results for generalized $\alpha$-contractive mappings. Univ. Politeh. Buchar. Sci. Bull., Ser. A 75(2), 3-10 (2013)

26. Rezapour, S, Hasanzade Asl, J: A simple method for obtaining coupled fixed points of $\alpha$ - $\psi$-contractive type mappings. Int. J. Anal. 2013, Article ID 438029 (2013)

27. Baleanu, D, Rezapour, S, Mohammadi, H: Some existence results on nonlinear fractional differential equations. Philos. Trans. R. Soc. Lond. A 371, 20120144 (2013)

28. Hasanzade Asl, J, Rezapour, S, Shahzad, N: On fixed points of $\alpha$ - $\psi$-contractive multifunctions. Fixed Point Theory Appl. 2012, $212(2012)$

29. Mohammadi, B, Rezapour, S, Shahzad, N: Some results on fixed points of $\alpha$ - $\psi$-Ćirić generalized multifunctions. Fixed Point Theory Appl. 2013, 24 (2013)

30. Sessa, S: On a weak commutativity condition of mappings in fixed point considerations. Publ. Inst. Math. (Belgr.) 32(46), 149-153 (1982)

31. Jungck, G: Compatible mappings and common fixed points. Int. J. Math. Math. Sci. 9(4), 771-779 (1986)

32. Jungck, G, Rhoades, BE: Fixed point for set valued functions without continuity. Indian J. Pure Appl. Math. 29(3), 227-238 (1998)

33. Pant, RP: Common fixed points of noncommuting mappings. J. Math. Anal. Appl. 188, 436-440 (1994)

34. Haghi, RH, Rezapour, S, Shahzad, N: Some fixed point generalizations are not real generalizations. Nonlinear Anal. 74, 1799-1803 (2011)

10.1186/1687-1812-2014-175

Cite this article as: Cho and Bae: Fixed points of weak $\alpha$-contraction type maps. Fixed Point Theory and Applications 2014, 2014:175

\section{Submit your manuscript to a SpringerOpen ${ }^{\ominus}$ journal and benefit from:}

- Convenient online submission

- Rigorous peer review

- Immediate publication on acceptance

- Open access: articles freely available online

- High visibility within the field

- Retaining the copyright to your article

Submit your next manuscript at $>$ springeropen.com 